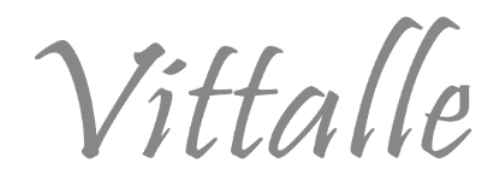

\title{
Relação entre reação leucemoide neutrofílica e doenças infecciosas
}

\author{
Isabella de Souza Mota ${ }^{a^{*}}$, Fabiola Fernandes dos Santos Castro ${ }^{\mathrm{b}}$ \\ a Pós-graduação em Hematologia Clínica e Laboratorial, Academia de Ciência e Tecnologia, \\ São José do Rio Preto, SP, Brasil

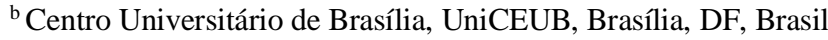

\section{Histórico do Artigo: Recebido em: \\ 23/11/2020 \\ Aceito em: \\ 25/04/2021}

Palavras-chave:

Neutrofilia; infecções bacterianas; virulência; microrganismo.

Keywords:

Neutrophilia; bacterial infections; virulence; microorganism.

\begin{abstract}
RESUMO
A reação leucemoide neutrofílica consiste em uma síndrome mieloproliferativa de caráter não maligno, sendo ocasionada por fatores que estimulam uma resposta exacerbada do sistema imune, comum em quadros infecciosos causados por microrganismos e seus fatores de virulência. Possui características passíveis de confusão com outras síndromes, como a leucemia mieloide crônica, sendo necessária a realização do diagnóstico diferencial. Objetivou-se realizar uma revisão da literatura por meio de livros, artigos inéditos e de revisão, além de relatos de caso sobre reação leucemoide e as principais doenças infecciosas vinculadas, buscando compreender qual tipo de microrganismo está mais associado e quais os motivos e agravantes relacionados. Foi realizada uma revisão da literatura científica no formato integrativo fundamentando o tema através do levante bibliográfico de artigos originais, livros, relatos de caso e artigos de revisão. O trabalho foi composto por publicações nos idiomas inglês, português e espanhol, compreendendo os anos 1926 a 2019. Foram valorizados os artigos que abordassem a reação leucemoide com proliferação de neutrófilos vinculada a processos infecciosos, sendo descartados publicações com a proliferação de outros leucócitos e mediada por processos neoplásicos, sendo mantidos 66 artigos. Dentre os diversos tipos de patógenos, a reação leucemoide neutrofílica está maior associada a infecções bacterianas. Isso se deve a particularidade de cada microrganismo em ativar a resposta imune, sendo as bactérias mais vinculadas a alta proliferação de neutrófilos devido aos seus fatores de virulência, como o LPS, por exemplo, podendo evoluir para uma síndrome de hiperviscosidade.
\end{abstract}

Relationship between neutrophilic leukemoid reaction and infectious diseases

\begin{abstract}
The neutrophilic leukemoid reaction consists of a non-malignant myeloproliferative syndrome, caused by factors that stimulate an exacerbated response of the immune system, common in infectious conditions caused by microorganisms and their virulence factors. It has characteristics that may be confusing with other syndromes, such as chronic myeloid leukemia, requiring a differential diagnosis. The objective was to carry out a literature review through books, unpublished and review articles, in addition to case reports on leukemoid reaction and the main related infectious diseases, seeking to understand which type of microorganism is most associated and what are the reasons and related aggravations. A review of the scientific literature was carried out in an integrative format, basing the theme through the bibliographic survey of original articles, books, case reports and review articles. The work consisted of publications in English, Portuguese and Spanish, covering the years 1926 to 2019. Articles that addressed the leukemoid reaction with proliferation of neutrophils linked to infectious processes were valued, publications with the proliferation of other leukocytes and mediated by neoplastic processes, with 66 articles being kept. Among the various types of pathogens, the neutrophilic leukemoid reaction is more associated with bacterial infections. This is due to the particularity of each microorganism in activating the immune response, with the bacteria being more linked to high proliferation of neutrophils due to their virulence factors, such as LPS, for example, which can evolve into a hyperviscosity syndrome.
\end{abstract}

\section{Introdução}

A reação leucemoide fora descrita em 1926 por Krumbhaar (1) sendo compreendida como um grupo de distúrbios mieloproliferativos que não possuem etiologia maligna. Hill

\footnotetext{
* Autor correspondente: isabellasmota11@gmail.com (Mota I.S.)
} 
e Duncan et al. (2) definiram como uma condição não neoplásica que ocasiona leucocitose (igual ou superior a 50.000 céls $/ \mathrm{mm}^{3}$ ) com intensa liberação de neutrófilos maduros no sangue periférico (contagem absoluta de 30.000 céls $/ \mathrm{mm}^{3}$ ), acompanhado de desvio a esquerda escalonado a mielócito e metamielócito, porém, sem alterações na série plaquetária e vermelha. A mieloproliferação não ocorre em todas as linhagens celulares, tendo como marcador a ausência de eosinófilos e basófilos (3).

A neutrofilia que acomete a reação leucemoide pode ser confundida com outras doenças de base mieloproliferativas, como a leucemia mielóide crônica (LMC) e a leucemia neutrofílica crônica (LNC). A principal diferença com a LMC é a ausência da translocação entre os braços longos dos cromossomos 9q34 e 22q11, que levam a síntese de uma proteína de fusão (híbrida) BCR-ABL, além da fosfatase alcalina neutrofílica negativa e desvio escalonado até mieloblasto. É necessário estudo citogenético e de imunofenotipagem, pois existem relatos onde pacientes com LMC não apresentam a formação da proteína BCRABL. Em se tratando da LNC, chega a ser impossível conseguir diferenciá-las, já que ambos os casos possuem alterações morfológicas parecidas e fosfatase alcalina neutrofílica positiva (4).

O processo da reação leucemoide ocorre como resposta exagerada a grandes inflamações, infecções bacterianas, sepse, hemorragias e intensa ativação do sistema complemento (5).

Revisando a literatura brasileira e estrangeira, é possível afirmar que a maior parte dos relatos de caso de reação leucemoide estão vinculados a doenças infecciosas. As infecções, de modo geral, estimulam o aumento da produção de leucócitos pela medula, além do aumento da atividade inflamatória do organismo. Cada processo infeccioso tem sua fisiopatologia própria, ativando células diferentes. As infecções bacterianas, por sua vez, elevam o número de neutrófilos, as virais os linfócitos, as parasitárias os eosinófilos e basófilos (6).

O diagnóstico é simples e deve ser feito como forma de exclusão para alterações malignas. Por ser uma resposta hematológica anormal que ocorre em virtude de uma situação de base infecciosa ou tumoral, a correção do problema primário resulta no controle da proliferação granulocítica.

A clínica do paciente concomitantemente ao resultado do hemograma contendo leucocitose com neutrofilia, fosfatase alcalina neutrofílica positiva e ausência da proliferação de blastos e de hiato leucêmico são um forte indicativo de reação leucemoide. Em caso de exclusão para doenças malignas, deve-se realizar a biópsia da medula óssea e o mielograma para melhor avaliação das células, tendo como resultado a ausência de fibrose e células displásicas.

É necessário avaliar possível exposição do paciente a metais pesados ou intoxicação por etilenoglicol, além da suplementação ou secreção por tumores de fatores de crescimento de colônias granulocíticas e/ou macrofágicas (G-CSF e GMCSF) ou interleucina 3, a qual é estimuladora de todas as linhagens hematopoiéticas (7).

Os neutrófilos presentes na reação leucemoide possuem atividade normal. São células que estão relacionadas a defesa do organismo contra patógenos e atuam no processo de englobamento (fagocitose) e destruição, fazendo parte da etapa inicial de defesa. São pertencentes a linhagem mielóide, correspondem a imunidade inata e são os leucócitos mais abundantes na corrente sanguínea (8), tendo o valor de referência, no adulto, entre 1800 a 7000 células $/ \mu \mathrm{L}$.

O processo de maturação dos neutrófilos corresponde a 14 dias, tendo o curto tempo de meia-vida na corrente sanguínea correspondente a 7,6 horas (9). Possuem alta capacidade fagocitária, microbicida, proteolítica e antioxidante, variando a atividade conforme o estágio de maturação celular e granulocítica (10). 
Tendo como base a importância da reação leucemoide neutrofílica e a carência de artigos que abordem de forma aprofundada sua relevância, correlações e prognóstico, este trabalho tem como objetivo realizar uma revisão da literatura, utilizando como base diversos meios de exposição de informações científicas, como artigos inéditos e de revisão, relatos de caso e livros que abordem sobre reação leucemoide e os principais microrganismos vinculados, buscando compreender qual tipo está mais associado, quais os motivos e agravantes relacionados.

\section{Método}

Através do levante bibliográfico proveniente de artigos publicados nas plataformas PubMed, ScieLo (Scientific Electronic Library Online), Biblioteca Virtual em Saúde (BVS), MEDLINE (Medical Literature Analysis and Retrieval System Online) e o buscador Google Acadêmico, foi realizada uma revisão da literatura científica no formato integrativo, utilizando como palavras-chave: neutrofilia; infecções bacterianas; virulência; microrganismo, sendo possível explicar porque alguns microrganismos estão vinculados a reação leucemoide neutrofílica.

Foram valorizados os artigos que estivessem dentro dos critérios de elegibilidade, tais como: abordar a temática da reação leucemoide envolvendo a proliferação de neutrófilos estando vinculado a processos infecciosos, fisiologia dos processos inflamatórios, infecciosos e mecanismo de ação dos neutrófilos.

Dentre os 240 artigos analisados, foram descartadas publicações com a reação leucemoide sendo mediada pela proliferação de outros leucócitos, como a reação leucemoide linfocítica, ou por processos tumorais, inflamatórios e neoplásicos, sendo mantidos 66 artigos no final da avaliação.

Deste modo, os trabalhos examinados variam entre os anos de 1926 a 2019 visando melhor fundamentar o tema e seus conceitos teóricos, sendo composto por artigos nos idiomas inglês, português e espanhol. Não foi necessário submeter o artigo ao Comitê de Ética em Pesquisa tendo em vista seu caráter de revisão de dados de domínio público já existentes na literatura científica.

\section{Resultados e Discussão}

\section{A reação leucemoide}

A reação leucemoide é denominada como um distúrbio mieloproliferativo de etiologia não maligna, evidenciando-se como uma leucocitose desregulada frente a necessidade de intensa resposta imune contra microrganismos, hematopoese ectópica ou estimulação da produção leucócitos através da suplementação de interleucina 3 e fatores de crescimento de colônias granulocíticas e/ou macrofágicas (GM-CSF). Algumas drogas como corticosteróides e as catecolaminas podem ocasionar a redução na adesão dos neutrófilos e aumento de sua produção (11).

Apesar de haver a mieloproliferação, esta é exclusiva dos neutrófilos, havendo ausência de basófilos e eosinófilos. As linhagens plaquetária e eritrocitária permanecem dentro dos padrões referenciais de normalidade para sexo e idade, podendo haver a presença de mielócitos e metamielócitos (3).

A reação leucemoide neutrofílica é a mais comum, tendo em vista que são os leucócitos mais abundantes no organismo e estão maiores vinculados a processos infecciosos. Porém, existem relatos de caso de reação leucemoide ocorrendo com outras células leucocitárias, como eosinófilos, monócitos e linfócitos. Nas bases de dados utilizadas para a pesquisa não foram encontrados relatos de caso acerca de reação leucemoide basofílica, fato este que pode estar vinculado ao número expressivamente pequeno dessas células no 
organismo, sendo zero um valor referencial normal para ambos os sexos (12).

Em adultos, a síndrome está associada a maior taxa de morbidade e mortalidade principalmente em pacientes com idade avançada e anêmicos (13), sendo 50\% dos casos relacionados a doenças infecciosas, tendo a sepse, pneumonia e infecções do trato urinário como as etiologias mais frequentes. A diarreia associada a infecção por Clostridium difficile shigelose e tuberculose também estão altamente vinculados $(14,15)$.

Em crianças, existem estudos, como o de Hoofien et al (16) que vinculam a reação leucemoide a maior probabilidade de desenvolvimento de pleuropneumonia e de maior tempo de internação frente a outros pacientes infantis sem alta no leucograma, apesar de não haver relação com o aumento da mortalidade. Neste estudo, foi possível observar que crianças com leucograma superior a 50.000 células/ $\mu \mathrm{L}$ possuem seis vezes mais chances de evoluir com leucemia.

A leucocitose está fortemente associada a hiperproliferação de neutrófilos, fagótico mais abundante na corrente sanguínea. Quando em casos de mieloproliferação não maligna, como na reação leucemoide, toda a linhagem neutrofílica possui citologia normal, sem apresentar vacuolização e sinais de citotoxicidade (2).

\section{Neutrófilos}

Os neutrófilos são células provenientes da linhagem mielóide, possuindo seis diferentes estágios de maturação: blasto, promielócito, mielócito, metamielócito, bastonete e neutrófilo segmentado. Sua maturação é estimulada pela presença de interleucinas específicas, como Fator Estimulador de Colônias Granulocíticas (G-CSF), sendo atraídos para o tecido através de interleucinas como IL-1, IL-6 e IL-8 (17).

Os neutrófilos maduros possuem núcleo multilobulado (dois a quatro lóbulos) interligados por um filamento de cromatina, podendo ser imperceptível através da visualização pelo microscópio óptico. Seu citoplasma é abundante, com granulações finas e rosadas, possuindo o diâmetro de 10 a $14 \mu \mathrm{m}$ (18).

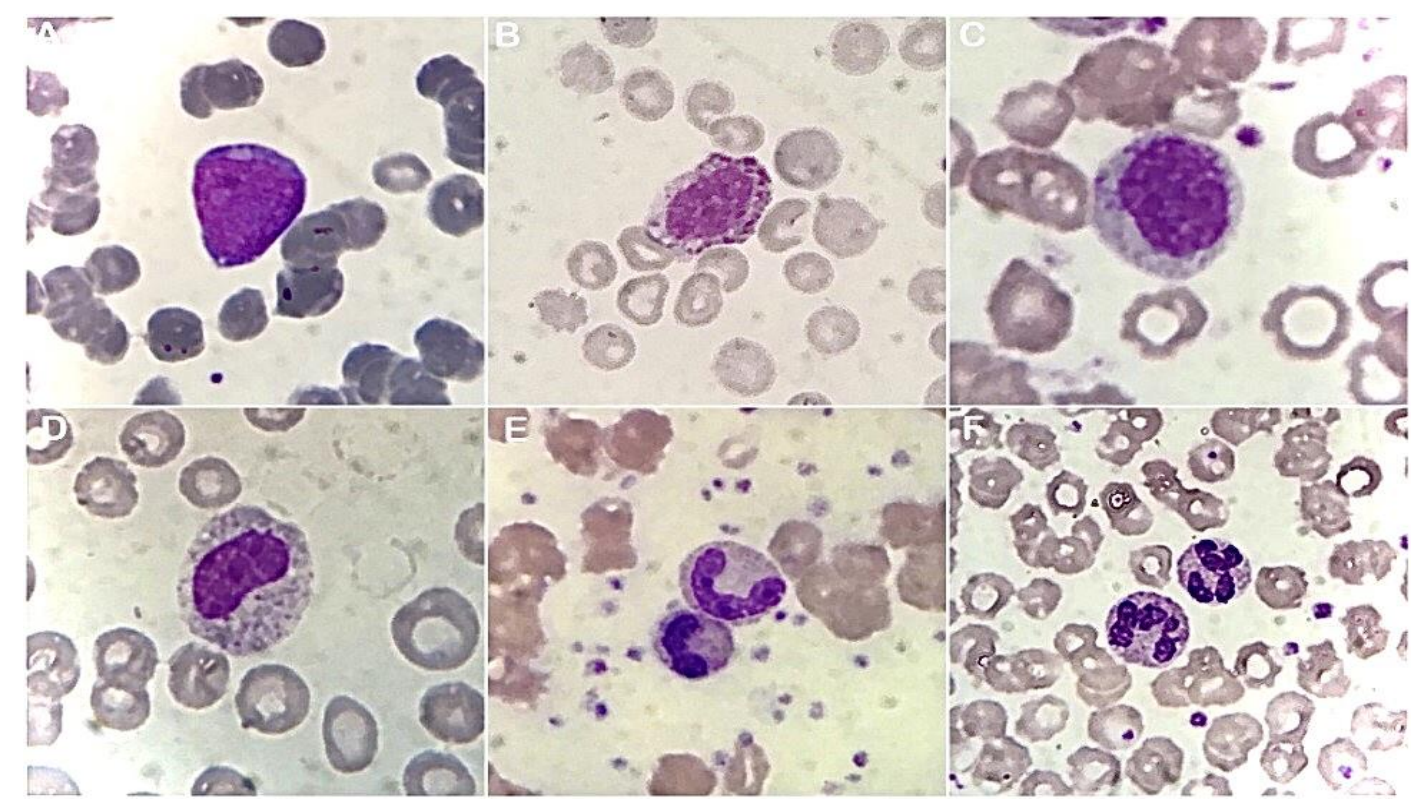

Figura 1 - Sequência de maturação da linhagem neutrofílica. Identificado em A há um blasto mielóide, seguido de promielócito em $\mathrm{B}$, mielócito em $\mathrm{C}$, metamielócito em $\mathrm{D}$, bastonete em E, e neutrófilo segmentado em F. Perceba que é possível notar a diferença de densidade de granulação de acordo com a maturação celular, tendo granulações mais marcantes e basofílicas no promielócito e rosadas e finas no neutrófilo maduro. 
Suas granulações são divididas em três partes: primárias (azurófilas), secundárias (específicas), terciárias (gelatinosas) e vesículas secretoras que se diferem de acordo com o estágio de maturação celular. Os grânulos primários estão presentes na fase inicial de maturação, são ricos em mieloperoxidase e pobres em defensinas, proteínas com atividade microbicida.

Os grânulos específicos predominam nos neutrófilos maduros e possuem como característica a mieloperoxidase negativa, presença de fosfatase alcalina e lactoferrina, proteína de transporte do ferro que auxilia na diminuição da produção de radicais livres, impedindo também o crescimento de determinados microrganismos. A granulação terciária é considerada um subtipo da secundária. Contém catepsinas, as quais possuem capacidade proteolítica (12).

As vesículas secretoras são uma zona de armazenamento que contém receptores de membrana que estão associados a mecanismos de fase inicial da resposta inflamatória. Possuem $\beta-2$ integrinas, receptores para CD14, CD16, CD11b, formilpeptídeo, CR1 (receptor para o sistema complemento). Quando ocorre o processo de rolamento do neutrófilo, os mecanismos contidos nas vesículas secretoras auxiliam principalmente na adesão endotelial. A membrana da vesícula se funde à membrana celular, permitindo a exocitose da integrina e maior adesão ao endotélio (19).

\section{Quimiotaxia dos neutrófilos}

A reação leucemóide pode estar associada a um comprometimento no processo de fagocitose e quimiotaxia dos neutrófilos (20), sendo fator de extrema importância tendo em vista que os neutrófilos atuam em resposta a situações como inflamações e infecções, onde a integridade celular é comprometida.

A migração dessas células se inicia com o processo de rolamento. Os neutrófilos passam a fluir próximo da parede endotelial através da associação dos receptores de superfície com os das projeções vilosas emitidas por essa célula. As principais moléculas integrantes desse processo são as selectinas (21).

Por possuírem baixa capacidade de adesão a selectina, os neutrófilos se ligam fracamente ao endotélio e se soltam pela pressão da corrente sanguínea, fazendo com que se desprendem e se liguem novamente, tendo esse processo nomeado de rolamento. A adesão de fato ocorre com a participação das integrinas, sua ligação aos receptores endoteliais e diversos fatores fisiológicos, como a diminuição da pressão arterial, que auxiliam a diapedese (22).

O rolamento do neutrófilo cessa quando ocorre a conexão da integrina aos seus ligantes na superfície do endotélio. O fator de necrose tumoral (TNF) e a IL-1 favorecem o aumento da expressão desses ligantes. A interleucina IL-8 tem um grande papel de sinalizar os locais de inflamação. Ela é secretada nesses locais levando a modificações na integrina, assim promovendo sua ligação com receptores endoteliais (23).

A principal atuação dos neutrófilos ocorre no processo de fagocitose, podendo muitos lisarem seu citoesqueleto devido ao excesso da atividade. A principal forma de reconhecer o microrganismo é através do processo de opsonização. As principais opsoninas (moléculas que se ligam ao antígeno, facilitando o processo de fagocitose) são anticorpos da classe IgG e a proteína C3b, que leva a ativação do sistema complemento. Essas partículas vão se aderir a receptores específicos nos neutrófilos, sendo um grupo específico para a proteína C3b e outro grupo para o fragmento Fc das IgGs (24).

Após o reconhecimento da partícula e sua fagocitose através do auxílio de seus pseudópodes, ocorre a formação do fagossomo. O microrganismo será digerido tanto pela ação das enzimas presentes nos grânulos, quanto pela produção de espécies reativas de 
oxigênio. A ação da mieloperoxidade é o que permite que os superóxidos formados sejam convertidos em peróxido de hidrogênio e depois em ácido hipocloroso, o qual possui propriedades desnaturantes para as proteínas presentes no microrganismo (12).

Outro mecanismo de proteção que é conferido aos neutrófilos é a NETose, um processo de suicídio celular onde o DNA intracelular é exposto, se ligando a proteínas granulares como a catepsina e a mieloperoxidase, formando um complexo de captura de patógenos, eliminando-os no meio extracelular (25).

\section{Possíveis complicações da reação leucemoide}

Nas doenças infecciosas, as complicações estão associadas aos mecanismos de patogenicidade e virulência do microrganismo envolvido. Porém, a leucocitose referente a reação leucemoide pode ocasionar a síndrome da hiperviscosidade, levando a hipotensão e hipoperfusão tecidual, podendo alterar os mecanismos de agregação plaquetária e aumentar o tempo de sangramento, sendo necessária a plasmaférese, hidratação e administração de hidroxiuréia. As alterações podem levar a insuficiência cardíaca e óbito, sendo mais comuns em pacientes leucêmicos (>100.000 células $/ \mathrm{mm}^{3}$ ) (26).

\section{Relação entre bactérias e a reação leucemoide neutrofílica}

Avaliando os relatos de caso de doenças infecciosas associadas a reação leucemoide, foi possível evidenciar que as intercorrências bacterianas mostraram maior prevalência quando comparadas com os outros tipos de agentes infecciosos, principalmente quando a bactéria possui mecanismos que conferem maior virulência, como endotoxinas, levando a uma resposta imune com ativação massiva do sistema complemento.

As bactérias Gram-negativas, Gram-positivas e as não coráveis pela metodologia de Gram, como os micoplasmas, treponemas e Bacilos Álcool-Ácido Resistentes (BAAR) possuem citologia diferente, conferindo capacidades distintas de ativar a resposta imune do organismo. De modo geral, possuem como estrutura comum citoplasma, ribossomo, membrana plasmática e nucléolo contendo DNA (27).

Existem diversos tipos de mecanismos que conferem maior virulência as bactérias, como o Lipopolissacarídeo (LPS), enzimas, toxinas e fatores de adesão, como a cápsula, podendo induzir uma resposta imune grave, possibilitando a evolução do quadro clínico para uma reação leucemoide neutrofílica.

\section{Toxina LPS}

As bactérias Gram-negativas possuem maior capacidade de resultar em choque séptico e intensa produção de granulócitos devida a presença do LPS em sua citologia. Sua estrutura é formada pelo lipídeo A, capaz de mediar intensa resposta inflamatória no organismo, polissacarídeo central, sendo uma identidade entre bactérias da mesma família, e polissacarídeo $\mathrm{O}$, servindo de mecanismo de diferenciação ${ }^{28}$. 
Vittalle - Revista de Ciências da Saúde v. 33, n. 2 (2021) 83-96

\section{ESTRUTURA DO LIPOPOLISSACARÍDEO}

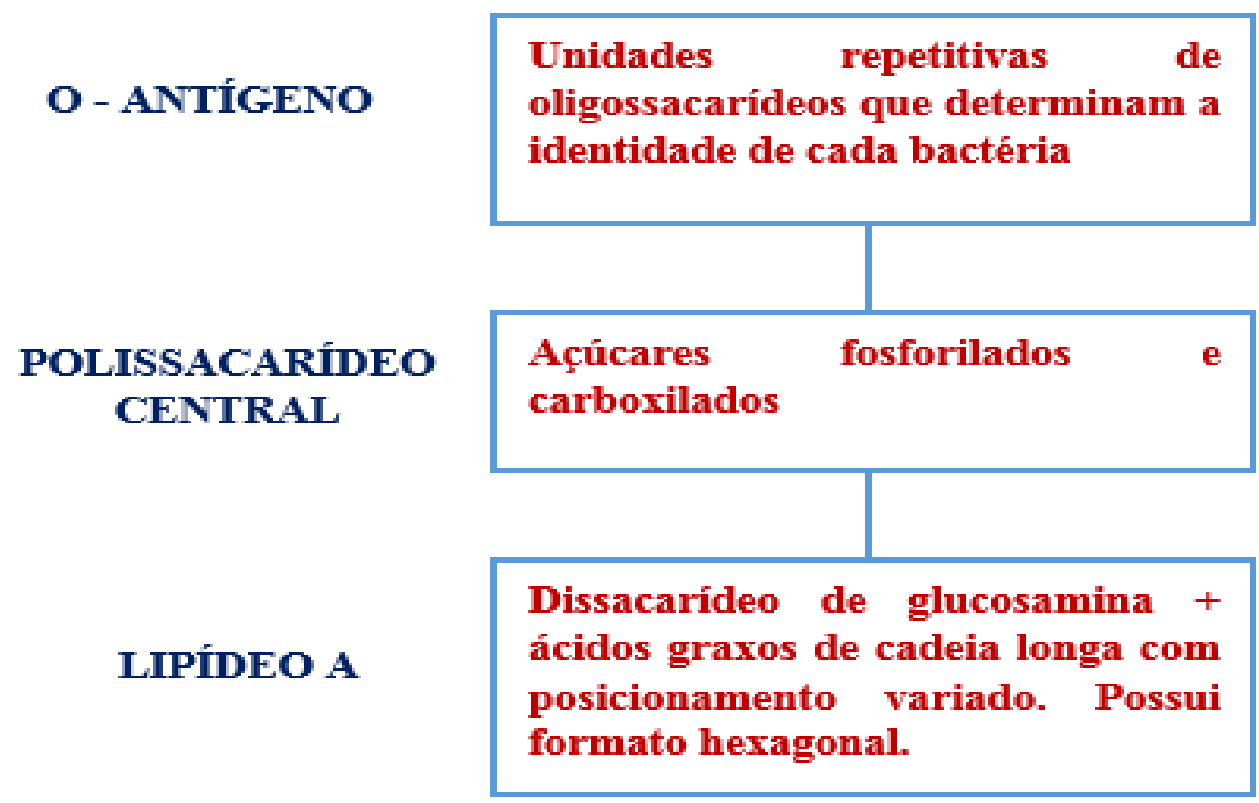

Figura 2 - Esquema representativo da estrutura do LPS.

Essa toxina inicia seu processo inflamatório após sua ligação com receptores específicos, principalmente de membrana celular, como o TLR4 (Toll-Like 4), proteína LBP (proteína ligante de LPS), proteína CD14 (componente do sistema imune inato), podendo estar circulante no citoplasma ou fixa em uma membrana celular, ou ligando-se a proteína mielóide diferenciadora 2 (MD-2) que também pode ser encontrada nas duas formas. Essas proteínas, quando livres no plasma, atuam transferindo o LPS para o receptor TLR4 ou para o complexo formado entre o receptor TLR4 e a proteína MD-2 (29). Esse complexo é considerado como a principal forma de reconhecimento do LPS.

A presença do LPS estimula fortemente a produção de neutrófilos, fibroblastos, macrófagos, células endoteliais, proteínas de fase aguda, ocasionando em uma produção acentuada de citocinas pró-inflamatórias (TNF- $\alpha$, IL-1, IL-6, IL-8), levando a apoptose celular. Seus efeitos são mediados principalmente pelo NFKB, um fator de transcrição de genes que estão relacionados à resposta inflamatória aguda. Ele se mantém inativo no citoplasma e migra para o núcleo após a interação do LPS com seus receptores (30).

A alta secreção de TNF- $\alpha$ (Fator de Necrose Tumoral alfa) (glicoproteína produzida por macrófagos e células mononucleares), principal proteína inflamatória de ação sistêmica envolvida em processos infecciosos, sendo principalmente estimulada pela presença do LPS, ocasiona morte celular, leucocitose e vasodilatação (má perfusão tecidual), levando a edemas e alterações cardiopulmonares (31).

Apesar do seu grande efeito sistêmico, estudos apontam que o LPS é capaz de ativar o sistema nervoso central (SNC) mesmo antes da ativação das proteínas de fase aguda, estimulando o hipotálamo anterior e alterando os mecanismos de termorregulação corporal (32). Essa resposta se dá pela presença de receptores CD14 e TLR4 nos órgãos circunventriculares, região altamente permeável, sem a presença da barreira hematoencefálica (BHE) (33).

A presença do LPS no organismo ocasiona maior expressão de G-CSF aumentando a sobrevivência celular, acelerando o processo de diferenciação e proliferação granulocítica principalmente da linhagem neutrofílica, sendo fator importante para o desenvolvimento da reação leucemoide (34).

As toxinas secretadas pela as bactérias possuem capacidade de estimular a reação 
inflamatória do organismo, ao ponto de se exacerbar em uma reação leucemoide. Elas são divididas pela forma que atuam na célula, podendo levar a lise e morte celular, perfurações na membrana, alteração de metabolismo, sendo grandes fatores de virulência.

\section{Superantígenos}

Os "superantígenos" são proteínas bacterianas capazes de estimular grande número de células T. Os estreptococos do grupo A (Streptococcus pyogenes) e o Staphylococcus aureus são exemplos de bactérias que produzem exotoxinas conhecidas como PTSAs (superantígenos de capacidade pirogênica). Os PTSAs possuem capacidade de desenvolver a síndrome do choque tóxico, também induzindo graves respostas imunes, com super estimulação da medula óssea. Existem estudos associando, também, algumas cepas de estreptococos do grupo B (35-37).

De modo geral, os PTSAs são proteínas de baixo peso molecular, possuindo de 20 a 30 KDa. Detém natureza endógena ou exógena. Sua principal diferença entre os antígenos comuns é a capacidade de ativar células T desencadeando as seguintes respostas: anergia, apoptose, pirogenicidade, autoimunidade e mitose de linfócitos $\mathrm{T}$, conferindo a eles a classe dos imunoestimuladores naturais mais potentes (38-40).

Por serem exotoxinas, possuem composição protéica e são solúveis em plasma, possuindo alto grau de imunogenicidade. De forma convencional, todo antígeno estimula a produção de anticorpos de ação neutralizante, onde irá ocorrer a ativação do linfócito TCD4 (internalização, processamento e reconhecimento entre antígenos e MHC classe II, permitindo a célula APC apresentar o peptídeo para a TCD4) (41).

O superantígeno se acopla diretamente ao MHC de classe II e ao TRC (receptor do linfócito T), não passando pela as etapas de internalização e processamento, levando a alta ativação de linfócitos. Com o sistema imune reconhecendo padrões moleculares associados a patógenos (PAMPs) das bactérias, ocorre a diferenciação de linfócitos TH1 e a indução da produção de diversas citocinas associadas, elevando interferon-gama (INF$\gamma$ ), interleucinas pró-inflamatórias e TNF- $\alpha$, favorecendo a alta quimiotaxia de neutrófilos e alterações vasculares ${ }^{42}$.

\section{Toxinas A e B do Clostridium difficile}

A reação leucemoide causada pela infecção gastrointestinal por Clostridium difficile possui prognóstico ruim e alto risco de mortalidade em adultos (43). As principais complicações associadas são hipotermia e hipoalbuminemia, tendo o desenvolvimento da reação leucemoide como fator que aumenta a taxa de mortalidade da infecção, chegando a $100 \%$ quando a contagem de leucócitos for superior a 50.000 células $/ \mathrm{mm}^{3}$.

Um estudo retrospectivo realizado por Marinella et al. (44) analisou, entre os anos de 1998 e 1999, relatos de caso de pacientes com teste fecal positivo para Clostridium difficile associado a contagem de leucócitos superior a 35.000 células $/ \mathrm{mm}^{3}$ obtendo como resultado pacientes com valor aumentado de hematócrito e infecção do trato respiratório. Todos os pacientes com alta contagem de leucócitos morreram (50.000 células $/ \mathrm{mm}^{3}$ ), tendo apenas $10 \%$ de mortes nos pacientes com contagem inferior.

As toxinas envolvidas na infecção por Clostridum difficile são conhecidas como A e B, a maior parte das cepas que constituem a microbiota intestinal dos animais e do homem as produz. Os mecanismos de atuação dessas toxinas não são totalmente conhecidos, porém, organismos que possuem cepas não produtoras das toxinas não são capazes de sofrerem doenças diarréicas associadas a este microrganismo $(45,46)$.

A toxina A é classificada como enterotoxina, responsável pelo sintomas 
gastrointestinais e intoxicação alimentar, e a toxina B como citotoxina, possuindo cerca de mil vezes mais potencial citotóxico que a toxina A. Detém em maior parte da sua composição os aminoácidos aspargina, glicina e glutamina, sendo a toxina A composta por uma sequência de 2710 aminoácidos e a B, $2366(47,48)$.

A toxina A estimula a produção de interleucinas pró-inflamatórias, metabólitos do ácido araquidônico, substância $\mathrm{P}$ (neuromodulador inflamatório), produção do fator de necrose tumoral e aumento da permeabilidade vascular causado pela destruição das ligações intercelulares. A resposta inflamatória exacerbada associada aos potentes efeitos citotóxicos de alteração citoplasmática e desequilíbrio osmótico da toxina $\mathrm{B}$ interrompem as fibras de actina do citoesqueleto, levando à destruição do epitélio ocasionando a destruição do lúmen intestinal, impossibilitando a absorção de nutrientes e favorecendo a alteração da microbiota e proliferação bacteriana, ocasionando a quimiotaxia de neutrófilos e macrófagos (49).

\section{Mycoplasmas}

Os Mycoplasmas são as menores bactérias existentes, assemelhando-se ao tamanho de vírus (150 a $300 \mathrm{~nm}$ ) tendo genoma com dimensões menores comparado ao de outras bactérias, porém, possuem capacidade de ativar o sistema imune de forma massiva quando em casos de imunossupressão, idade elevada ou em crianças. São a segunda maior causa de pneumonia adquirida na comunidade (PAC), sendo por Streptococcus pneumoniae a mais comum $(50,51)$.

A ausência da parede celular confere maior capacidade de polimorfismo e resistência a antimicrobianos $\beta$-lactâmicos. Os quadros infecciosos eventualmente progridem para a cronificação devido sua capacidade de invadir células eucarióticas. Sua patogenicidade está relacionada com a alta capacidade de variabilidade dos antígenos de superfície, indução da expressão dos complexos de histocompatibilidade I e II, produção exotoxinas, proteases, hemolisinas membranares, além de superantígenos $(52,53)$.

De modo geral, as infecções por mycoplasma não evoluem para complicações, a contagem de leucócitos em 70 a $95 \%$ dos casos permanece dentro dos valores referenciais para sexo e idade ${ }^{54}$. Apesar de não haver complicações relacionadas, em 50 a $75 \%$ das infecções ocorre a produção de crioaglutininas, resultando em hemólise subclínica, com reticulocitose e leucocitose em 30\% dos casos, podendo persistir por até três meses. As intercorrências podem evoluir para um quadro de anemia hemolítica aguda grave associada a reação leucemoide, porém, poucos relatos de caso foram descritos (55-57).

A reação leucemoide na infecção por Mycoplasma está associada a atividade exacerbada da medula óssea em combater os mecanismos de patogenicidade presentes na bactéria e a intensa atividade do sistema complemento em casos de evolução da hemólise subclínica para anemia hemolítica aguda grave, onde as crioaglutininas se ligam ao antígeno I presente na superfície das hemácias, desencadeando a ação das proteínas do sistema complemento.

Existe a possibilidade da bactéria, através da produção de peróxido de hidrogênio, alterar a estrutura do polissacarídeo I tornando-o antigênico, ou de forma desconhecida, ele se tornar uma espécie de receptor para o mycoplasma, fazendo com que os anticorpos se desloquem até esse receptor modificado e iniciem o processo de destruição da hemácia $(58,59)$.

Em algumas regiões do organismo, como no trato urinário, as bactérias precisam de mecanismos de adesão para serem capazes de permanecerem por mais tempo fixados no tecido, possibilitando a infecção. Para que a adesão ocorra de maneira eficaz, é necessário haver compatibilidade físico-química entre as substâncias localizadas na superfície celular bacteriana, como também das características do tecido (60). 


\section{Adesinas}

As principais substâncias envolvidas no processo de adesão são as adesinas. Também conhecidas como fímbrias, as adesinas são estruturas protéicas que podem se apresentar de forma fimbrial com pili compostas por hetero-polímeros de várias subunidades e nãofimbrial constituídas por uma única proteína ou homotrímeros. Algumas bactérias são capazes de expressar diferentes tipos de adesinas ao mesmo tempo, modificando seu potencial de virulência (61). Cada tipo de adesina está envolvida em funções diferentes, podendo também levar a formação de biofilmes bacterianos (62).

As fímbrias são usualmente mais comuns em bactérias Gram-negativas, porém, estreptococos do grupo B produzem fatores de adesão similares. Elas podem estar dispostas por toda a célula bacteriana ou voltadas a uma extremidade, podendo cada fímbria possuir função diferente. Em sua composição proteica é encontrada a pilina, que forma o pilus após sofrer o processo de polimerização. A composição química da fímbria indica a forma que ela é capaz de se aderir ao tecido, por exemplo, as pili do tipo I, através de ligação por manose, são capazes de se aderir as uroplaquinas que revestem o urotélio, sendo encontradas em algumas cepas de Escherichia coli, principal bactéria causadora de infecção do trato urinário (63).

A maior capacidade de fixação do microrganismo é fator de risco para um maior estímulo do sistema imune, visto que a bactéria e seus fatores de virulência persistem por mais tempo, causando maior ativação de fagócitos e mecanismos de defesa, como vasodilatação e liberação de citocinas pró-inflamatórias.

\section{Toxina de shiga - Shigella spp.}

As enterobactérias do gênero Shigella são classificadas como bastonetes Gramnegativos imóveis e anaeróbios, fortemente associados a graves desinterias inflamatórias, podendo evoluir para síndrome hemolítico-urêmica e prolapso retal. Rahaman et al (64) .e Koster et. al. (65) reportaram associações entre a reação leucemoide vinculada a Shigella dysenteriae, produtora da toxina shiga, e a síndrome hemolítico-urêmica, sendo a reação leucemoide um indicador de mau prognóstico em crianças.

Um estudo realizado por Butler (11) avaliou se haveria o desenvolvimento de reação leucemoide em 3573 pacientes com shigelose em um hospital em Bangladesh. 136 (3,8\%) pacientes internados manifestaram reação leucemoide, sendo $78 \%$ crianças com idade inferior a 4 anos. A Shigella dysenteriae foi o principal tipo envolvido em pacientes com a reação leucemoide, sendo presente em $71 \%$ dos casos (96 pacientes), indicando um possível fator de virulência nesse sorotipo que ocasione a evolução do quadro para a reação.

Nos pacientes que cursaram de forma normal a shigelose, 2119 (62\%) apresentaram Shigella flexneri. Ao comparar a letalidade entre paciente com e sem reação leucemoide, foi possível observar grande discrepância, sendo $7.3 \%$ em pacientes normais e $21 \%$ nos pacientes que desenvolveram a reação. Na contagem de leucócitos dos pacientes que apresentaram a reação leucemoide, notou-se uma média de 66.000 células/mm3 incluindo a presença de bastonetes, metamielócitos e mielócitos.

As correlações clínicas que levaram ao óbito os pacientes com reação leucemoide foram anemia hemolítica, insuficiência renal e em 39 pacientes o desenvolvimento da síndrome hemolítica urêmica. Apesar de não haver nas bases de dados utilizados para a pesquisa artigos que relacionem diretamente as shiga toxinas com o desenvolvimento da reação leucemoide, é de conhecimento que a Shigella dysenteriae produz shiga 1 e shiga 2 (stx1 e stx2, respectivamente), responsáveis pela estimulação de IL-8, anteriormente 
denominada como fator quimiotático de neutrófilos (66), sendo possivelmente um fator diferencial que favoreça o acometimento da reação.

\section{Outros microrganismos}

Os mecanismos de virulência dos fungos como o da paracoccidioidomicose, vírus como o citomegalovírus (CMV) e parasitas como o da toxocaríase e o Plasmodium falciparum, apesar de potencialmente perigosos, não estão fortemente vinculados a reações leucemoides neutrofílicas, tendo poucos casos descritos na literatura. Inclusive, vale ressaltar que existem relatados mais casos de neoplasias como sarcomas associados a reações leucemoides do que infecções, por exemplo, parasitárias, sendo estas mais comuns em animais do que em humanos. Isso se deve a particularidade de cada microrganismo em ativar a resposta imune, sendo as bactérias mais vinculadas a alta proliferação de neutrófilos.

Quadro 1 - Resumo relacionando os fatores de virulência bacterianos com o mecanismo de ação correlacionado.

\begin{tabular}{|l|l|}
\hline \multicolumn{1}{|c|}{ Fatores de virulência } & \multicolumn{1}{|c|}{ Mecanismo de ação } \\
\hline Lipopolissacarídeo & $\begin{array}{l}\text { Processo inflamatório agudo mediado por NKFB } \\
\text { e intensa estimulação de G-CSF; }\end{array}$ \\
\hline Superantígenos & $\begin{array}{l}\text { Mitose de linfócitos T; quimiotaxia de } \\
\text { neutrófilos; }\end{array}$ \\
\hline $\begin{array}{l}\text { Toxinas A e B do Clostridium } \\
\text { difficile }\end{array}$ & $\begin{array}{l}\text { Potente efeito enterotóxico e citotóxico; } \\
\text { modificação da microbiota com intensa } \\
\text { leucocitose; }\end{array}$ \\
\hline Mycoplasmas & $\begin{array}{l}\text { Polimorfismo e variabilidade dos antígenos de } \\
\text { superfície ocasionam maior ativação do sistema } \\
\text { imune; produção de crioaglutininas; }\end{array}$ \\
\hline Adesinas & $\begin{array}{l}\text { Aumento do tempo de permanência dos } \\
\text { mecanismos de virulência bacterianos no } \\
\text { organismo, acentuando o processo inflamatório; }\end{array}$ \\
\hline Toxina de Shiga - Shigella spp & $\begin{array}{l}\text { Intensa ativação de IL-8 (anteriormente descrito } \\
\text { como fator quimiotático de neutrófilos). }\end{array}$ \\
\hline
\end{tabular}

\section{Considerações finais}

Tendo em vista as informações obtidas através da revisão da literatura, pode-se concluir que a reação leucemoide neutrofílica é uma síndrome mieloproliferativa de simples diagnóstico, porém com tratamento relativo, variando conforme a doença de base que está ocasionando a proliferação granulocítica. Está fortemente associada a infecções bacterianas, principalmente mediadas pelo lipopolissacarídeo (LPS), sendo um importante fator de virulência por ativar a leucocitose de diferentes maneiras e de forma simultânea. As toxinas A e B do Clostridium difficile, os Mycoplasmas e a toxina de shiga possuem quadro clínico mais grave quando associados a reação leucemoide, porém, esse vínculo é mais raro.

As bactérias possuem maior relação com o processo de reação leucemoide neutrofílica devido sua gama de fatores de virulência e patogenicidade que implicam em maior exacerbação da atividade do sistema imune frente a outras infecções, como as virais, fúngicas e parasitárias. 


\section{Referências}

1. Krumbhaar EB. Leukemoid blood picture in various clinical conditions. The American Journal of Medicine. 1926; 172:519-33.

2. Hill JM, Duncan CN. Leukemoid reactions. The American Journal of Medicine. 1941; 210:847-857.

3. Curnutte JT, Coates TD. Disorders of phagocyte function and number. In: Hoffman R, Benz JR, Shattil SJ. Hematology: basic principles and practice. 3 ed. Philadelphia: Churchill Livingstone; 2000. p. 740.

4. Bohm J, Kock S, Schaefer HE, Fisch P. Evidence of clonality in chronic neutrophilic leukaemia. Journal of Clinical Pathology, 2003; 56(4): 292-295.

5. Dale DC, Beutler E, Lichtman MA, Coller BS, Kipps TJ, Seligsohn U. Neutropenia and neutrophilia. In: DAVID, C.; KARL, W. Williams Hematology. 6 ed. New York: McGraw-Hill, 2001. p. 831.

6. Muller WA. Mechanisms of transendothelial migration of leukocytes. Circulation Research. 2009; 105: 223-230.

7. Leonard BJ, Israels MC, Wilkison J.F. Alkaline phosphatase in the white cells in leukaemia and leukemoid reactions. The Lancet. 1958; 1(7015): 289-92.

8. Nathan C. Neutrophils and immunity: challenges and opportunities. Nature Reviews Immunology 2006; 6(3): 173-8.

9. Hager M, Cowland JB, Borregaard N. Neutrophil granules in health and disease. Journal of Internal Medicine. 2010; 268(1): 25-34.

10. Bratton DL, Henson PM. Neutrophil clearance: when the party is over, cleanup begins. Trends in Immunology. 2011; 32(8): 350-7.

11. Butler T, Islam MR, Bardhan PK. The leukemoid reaction in shigellosis. The American Journal of Diseases of Children. 1984; 138(2): 162-5.

12. Zago MA, Falcão RP, Pasquini R. Tratado de hematologia. São Paulo: Atheneu, 2013.

13. Portich JP, Faulhaberm GAM. Leukemoid reaction: A 21 st-century cohort study. International Journal of Laboratory Hematology. 2020; 42(2): 134-139.

14. Potasman L, Grupper M. Leukemoid reaction: spectrum and prognosis of 173 adult patients. Clinical Infectious Diseases. 2013; 57(11): e177-81.

15. Ellison TA, Mandal K. Leukemoid reaction: Case report. The Journal of Thoracic and Cardiovascular Surgery. 2018; 155(4):e117-e118.

16. Hoofien A, Yarden-Bilavski H, Ashkenazi S, Chodick G, Livni G. Leukemoid reaction in the pediatric population: etiologies, outcome, and implications. European Journal of Pediatrics. 2018; 177(7):10291036.

17. Silva IC. Neutrófilos: aspectos clássicos, plasticidade e novas funções imunorregulatórias. Revista Interdisciplinar de Estudos Experimentais. 2015; 7: 35-46

18. Williams WJ, Beutler E, Erslev AJ, Rundles RW. Hematologia. Rio de Janeiro: Guanabara Koogan, 1990.

19. Faurschou M, Borregaard N. Neutrophil granules and secretory vesicles in inflammation. Microbes and Infection 2003; 5(14): 1317-1327.

20. De Martins M, Modesti M, Ginaldi L. Phenotypic and functional changes of circulating monocytes and polymorphonuclear leucocytes from elderly persons. Immunol Cell Biol. 2004; 82(4): 415-20.

21. Wagner JG, Roth RA. Neutrophil migration mechanisms, with an emphasis on the pulmonary vasculature. Pharmacological Reviews. 2000; 52(3): 349-74.

22. Burg ND, Pillinger MH. The neutrophil: function and regulation in innate and humoral immunity. Clinical Immunology. 2001; 99(1): 7-17.

23. Sheppard FRM. Structural organization of the neutrophil NADPH oxidase: phosphorylation and translocation during priming and activation. Journal of Biology. 2005; 78(5): 1025-42.

24. Bechara GH. O processo inflamatório: componentes e eventos celulares. UNESP. São Paulo, 2006. Disponível

em: https://www.fcav.unesp.br/Home/departamentos/patologia/GERVASIOHENRIQUEBECHARA/INF LAM_2006.pdf.

25. Kaplan MJ, Radic M. Neutrophil extracellular traps: double-edged swords of innate immunity. Journal of Immunology. 2012; 189(6): 2689-95.

26. Roath S, Davenport P. Leukocyte numbers and quality: their effect on viscosity. Clinical \& Laboratory Haematology. 1991; 13(3):255-62

27. Tortora GJ, Funke BR, Case CL. Microbiologia. 12. ed. Porto Alegre: Artmed; 2017.

28. Rietschel ET, Kirikae T, Shcade FU, Mamat U, Schmidt G, Loppnow H, Ulmer AJ, Zahringer U, Seydel U, Padova FD, Schreier M, Brade H. Bacterial endotoxin: molecular relationships of structure to activity and function. The FASEB Journal. 1994; 8(2): 217-25.

29. Shimazu R, Akashi O, Ogata H, Nagai Y, Fukudome K, Miyake K, Kimoto M. MD-2, a molecule that 


\section{Vittalle - Revista de Ciências da Saúde v. 33, n. 2 (2021) 83-96}

confers lipopolysaccharide responsiveness on Toll-like receptor. Journal of Experimental Medicine. 1999; 189(11): 1777-82.

30. Raetz CR, Whitfield C. Lipopolysaccharide endotoxins. Annual Review of Bioochemistry. 2002; 71: 635-700.

31. Meffert MK, Baltimore D. Physiological functions for brain NF-кB. Trends in Neurosciences. 2005; 28(1): 37-43.

32. Rivest, S. Molecular insights on the cerebral innate immune system. Brain, Behavior and Immunity. 2003; 17(1): 13-9.

33. Laflamme N, Rivest S. Toll-like receptor 4: The missing link of the cerebral innate immune response triggered by circulating gram-negative bacterial cell wall components. The FASEB Journal. 2001; 15(1): 155-163.

34. Lucidi CA, Takahira RK. Granulocyte colony-stimulating factor use in neutropenias in dogs and cats. Ciência rural. 2007; 37(3): 915-920.

35. Sissons JG. Superantigens and infections diseases. The Lancet. 1993; 341(8861): 1627-9.

36. Schmalts R, Bhogal B, Wang Y. Staphylococcal Enterotoxin is a bovine $\mathrm{T}$ cell superantigen. Immunological investigations. 1995; 24(5): 805-18.

37. Scwab JH, Brown RR, Anderle SK. Reactivation of bacterial cell wall induced arthritis and alteration of T cells by native and mutant superantigen. The Annals of the Rheumatic Diseases. 1995; 54: 524.

38. Lone SK, Ole B. Superantigens. Do they have a role in skin disease? Archives of dermatology. 1995; 131(7): 829-32.

39. Le Bon A, Lucas B, Vasstur F. In vivo T cell reponse to viral superantigen Selective migration rather than proliferation. Journal of Immunology. 1996; 156(12): 4602-8.

40. Vanier LE. Studies on peripheral T-Cell deletion and anergy induced by superantigens. Journal of Experimental Medicine. 1992; 176: 37-46.

41. Coico R, Sunshine, G. Imunologia. 6 ed. Brasil: Guanabara; 2010.

42. Proft T, Fraser JD. Bacterial superantigens. Clinical and Experimental Immunology. 2003; 133(3): 299306.

43. Naaraayan A, Aleta M, Basak P, Jesmajian S, Goldstein R. Leukemoid reaction to Clostridium difficile infection. Anaerobe. 2015: 34:158-60.

44. Marinella MA, Burdette SD, Bedimo, R.; Markert, R.J. Leukemoid reactions complicating colitis due to Clostridium difficile. Southern Medical Journal. 2004; (10): 959-63.

45. Bartlett JG. Clostridium difficile: Clinical considerations. Review of Infectious Diseases. $1990 ; 12$ Suppl 2: S243-51.

46. Kelly CP, Pothoulakis C, Lamont JT. Clostridium difficile colitis. The New England Journal of Medicine. 1994; 330(4): 257-62.

47. Barroso LA, Wang SZ, Phelps CL, Johnson JL, Wilkins TD. Nucleotide sequence of Clostridium difficile toxin B gene. Nucleic Acids Research. 1990; 18(13): 4004.

48. Dove $\mathrm{CH}$, Wang SZ, Price SB, Phelps CJ, Lyerly DM, Wilkins TD, Johnson JL. Molecular characterization of the Clostridium difficile toxin A gene. Infection and Immunity. 1990; 58(2): 4808.

49. Ananthakrishnan AN, Issa M, Binion DG. Clostridium difficile and inflammatory bowel disease. Gastroenterology Clinics of North America. 2010; 94(1): 135-53.

50. Costa, MJM. Infecção por Mycoplasma e Clamydia. In: LOPES, A.C. Tratado de Clínica Médica, São Paulo: Roca, 2006.

51. Wilson MH, Collier AM. Ultrastructural study of Mycoplasma pneumoniae in organ culture. Journal of Bacteriology. 1976; 125(1): 332-9.

52. Baseman JB, Tully JG. Mycoplasmas: Sophisticated, remeerging, and burdened by their notoriety. Emerging Infectious Diseases. 1997; 3(1): 21-3

53. Waites KB, Bébéar CM, Robertson JA, Talkington DF, Kenny GE. Laboratory diagnosis of mycoplasmal infections. Israel Journal of Medical Sciences. 2001; 17: 697-728.

54. Marrie TJ. Mycoplasma pneumoniae pneumonia requiring hospitalization, with emphasis on infection in the elderly. JAMA Internal Medicine. 1993; 153(4):488-94.

55. Wilson ML, Menjivar E, Kalapatapu V, Hand AP, Garber J, Ruiz MA. Mycoplasma pneumoniae associated with hemolytic anemia, cold agglutinins, and recurrent arterial thrombosis. Southern Medical Journal. 2007; 100(2):215-7

56. Daxbock F, Zedtwitz-Liebenstein K, Burgmann H, Graninger W. Severe hemolytic anemia and excessive leukocytosis masking mycoplasma pneumonia. Annals of Hematology. 2001; 80(3): 180-2.

57. Kottayam R, Rozenberg G, Cohn RJ. Unusual haematologic manifestations of Mycoplasma pneumoniae infection. Journal of Pediatrics and Child Health. 2007; 43(1-2): 80-2

58. Waites KB, Talking DF. Mycoplasma pneumoniae and its role as a human pathogen. Clinical 
Microbiology Reviews. 2004; 17(4): 697-728.

59. Kirschfink M, Knoblauch K, Roelcke D. Activation of complement by cold agglutinins. Infusionsther Transfusionsmed. 1994; 21(6): 405-9.

60. Chaves L. Estudo da Cinética de Formação de Biofilmes em Superfícies em Contacto com Água Potável [Dissertação]. Braga: Universidade do Minho, Departamento de Engenharia Biológica; 2004.

61. Gerlach RG, Hensel R. Protein secretion systems and adhesins: the molecular armory of Gramnegative pathogens. International journal of medical microbiology. 2007; 297(6): 401-15.

62. Dunne JR. Bacterial adhesion: seen any good biofilms lately? Clinical Microbiology Reviews. 2002; 15(2): 155-66.

63. Nicolle LE. Epidemiology of urinary tract infection. Infections in medicine. 2001; 24: 135-140.

64. Rahaman MM, Khan MU, Aziz KMS, Islam S, Kibriya AKMG. An outbreak of dysentery caused by Shigella dysenteriae type I on a coral island in the Bay of Bengal. Journal of Infectious Diseases. 1975; 132(1): 15-9.

65. Koster F, Levin J, Walker L, Tung KSK, Gilman RH, Rahaman M, Williams RC. Hemolytic-Uremic Syndrome after Shigellosis. New England Journal of Medicine, 1978; 298: 927-933.

66. Amani J, Ahmadpour A, Imani Fooladi AA, Nazarian S. Detection of E. coli O157:H7 and Shigella dysenteriae toxins in clinical samples by PCR-ELISA. The Brazilian Journal of Infectious Diseases. 2015; 19(3):278-84. 